Tạp chí Cơ Học Journal of Mechanics, NCSR of Vietnam T. XIV, 1992, No $2(7-12)$

\title{
NONLINEAR MODEL SIMULATION OF SHIP MOTION
}

\author{
NGUYEN VAN DAO
}

Institute of Mechanics NCSR Vietnam

\begin{abstract}
SUMMARY. Nonlinear model simulation of coupling between heave - roll and pitch roll ship motions is considered by means of the aymptotic method of nonlinear mechanics. The purely vertical motion and vertical - angular motion and their stability are studied.
\end{abstract}

\section{INTRODUCTION}

The simulation of the coupling between heave roll and pitch roll motions of a ship running in a regular longitudinal or oblique sea has been studied by Tondl A. and Nabergoj R. [1]. The proposed model consists of a mass $M$ restrained by a linear elastic spring, which, in turn, carries a simple free oscillating pendulum made up of a mass $m$ attached to a hinged, weightless rod (Fig. 1). The system is forced to oscillate sinusoidally in the vertical direction by means of an external driver with constant amplitude $q$ and frequency $\omega$. The coupling between the vertical and angular oscillations is accomplished by connecting the two inasses and the effect of the waves is simulated by means of external forcing.

In the present paper some results obtained by Tondl A. and Nabergoj R. $[1,2]$ will be extended for the case of a nonlinear elastic spring and nonlinear expansions of trigonometric functions.

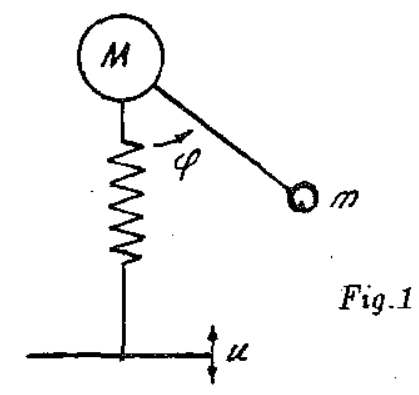

\section{MOTION EQUATIONS}

Using the Lagrange equations for the system represented in Fig.1 we have the following differential equations of motion:

$$
\begin{aligned}
& (m+M)(\bar{Z}+\bar{u})+k_{0} Z+\beta_{u} Z^{3}+h_{0} \dot{Z}+m \ell\left(\ddot{\varphi} \sin \varphi+\dot{\varphi}^{2} \cos \varphi\right)=0, \\
& m \ell^{2} \bar{\varphi}+C_{0} \dot{\varphi}+m \ell(g+\bar{Z}+\bar{u}) \sin \varphi=0,
\end{aligned}
$$

where $Z=x-u$ is the relative vertical displacement of the mass $M, x$ is the vertical displacement of the unass $M$ from its static position of equilibrium, $u=q \cos \omega t$ is the vertical displacement of the base of the spring - mass system, $\varphi$ is the angular displacement of the pendulum, $k_{0}$ and $\beta_{i}$ are the linear and nonlinear characteristics of the spring respectively, $\ell$ is the length of the rod, 
$h_{0}$ and $C_{0}$ are the damping coefficients of the linear and angular motions, respectively, $g$ is the gravity acceleration and an overdot denotes a derivative with respect to time $t$.

By introducing the notations

$$
\begin{aligned}
& w=\frac{Z}{\ell}, \quad \eta=\frac{\omega}{\omega_{0}}, \quad \omega_{0}=\sqrt{\frac{g}{\ell}}, \quad c=\frac{C_{0}}{\omega_{0} m \ell^{2}}, \\
& h=\frac{h_{0}}{\omega_{0}(m+M)}, \quad k^{2}=\frac{k_{0}}{\omega_{0}^{2}(m+M)}, \quad \beta=\frac{\beta_{i,} \ell^{2}}{\omega_{0}^{2}(m+M)}, \\
& \mu=\frac{m}{m+M}, \quad \sigma=\frac{g}{\ell}, \quad \tau=\omega_{0} t_{1}
\end{aligned}
$$

and supposing that the damping forces and the ratios $\frac{q}{\ell}=\sigma, \frac{m}{m+M}=\mu$ are small, and limiting by considering small vibrations of coordinates, so that $w^{3}, \varphi^{3}, \varphi \varphi^{\prime \prime}, \varphi^{\prime 2}, \varphi w^{\prime \prime}$ are small, we have the following equations of motion:

$$
\begin{aligned}
w^{\prime \prime}+k^{2} w & =-\varepsilon f\left(w, w^{\prime}, \varphi, \varphi^{\prime}, \varphi^{\prime \prime}\right)+\varepsilon^{2} \ldots \\
\varphi^{\prime \prime}+\varphi & =\varepsilon \Phi\left(w^{\prime \prime}, \varphi, \varphi^{\prime}\right)+\varepsilon^{2} \cdots
\end{aligned}
$$

where a prime denotes a derivative with respect to the dimensionless time $\tau$,

$$
\begin{aligned}
& f=-\sigma \eta^{2} \cos \eta \tau+h w^{\prime}+\beta w^{3}+\mu\left(\varphi \varphi^{\prime \prime}+\varphi^{\prime 2}\right) \\
& \Phi=-c \varphi^{\prime}+\frac{\varphi^{3}}{6}-\varphi w^{\prime \prime}+\sigma \eta^{2} \varphi \cos \eta \tau
\end{aligned}
$$

and $\varepsilon$ is a small dimensionless positive parameter that is used as a book keeping device and will be set equal to unity in the final results. The case $\beta=0, \sin \varphi \approx \varphi, \cos \varphi \approx 1$ has been examined in $[1,2]$.

\section{APPROXIMATE SOLUTION}

Let us consider the resonant region determined by

$$
\begin{aligned}
& k^{2}=\eta^{2}-\varepsilon \Gamma \\
& \eta^{2}=4(1+\varepsilon \Delta)
\end{aligned}
$$

where $\Gamma$ and $\Delta$ are detuning parameters. Using in equations (2.3) the transformation into new amplitude and phase variables $R, \theta, a, \psi$ by means of the formulae

$$
\begin{array}{ll}
w=R \cos \xi, & w^{\prime}=-R \eta \sin \xi, \quad \xi=\eta \tau+\theta, \\
\varphi=a \cos \alpha, & \varphi^{\prime}=-\frac{1}{2} a \eta \sin \alpha, \quad \alpha=\frac{1}{2} \eta \tau+\psi,
\end{array}
$$

we have:

$$
\begin{aligned}
& \eta R^{\prime}=\varepsilon(f-\Gamma w) \sin \xi ; \quad \eta a^{\prime}=-2 \varepsilon(\Phi+\Delta \varphi) \sin \alpha \\
& R \eta \theta^{\prime}=\varepsilon(f-\Gamma w) \cos \xi ; \quad \eta a \psi^{\prime}=-2 \varepsilon(\Phi+\Delta \varphi) \cos \alpha .
\end{aligned}
$$

These equations are in the standard form for which the averaging technique of nonlinear mechanics [3] can be used. So, in the first approximation one can replace (3.3) by the following evaraged equations: 


$$
\begin{aligned}
R^{\prime} & =-\frac{\varepsilon}{2}\left[h R+\sigma \eta \sin \theta+\frac{1}{4} \mu \eta a^{2} \sin (\theta-2 \psi)\right], \\
R \eta \theta^{\prime} & =-\frac{\varepsilon}{2}\left[\Gamma R-\frac{3}{4} \beta R^{3}+\sigma \eta^{2} \cos \theta+\frac{1}{4} \mu \eta^{2} a^{2} \cos (\theta-2 \psi)\right], \\
a^{\prime} & =-\frac{\varepsilon}{2}[c a+\sigma \eta a \sin 2 \psi-R \eta a \sin (\theta-2 \psi)], \\
a \eta \psi^{\prime} & =-\frac{\varepsilon}{2}\left[2 \Delta a+\frac{1}{4} a^{3}+\sigma \eta^{2} a \cos 2 \psi+R \eta^{2} a \cos (\theta-2 \psi)\right] .
\end{aligned}
$$

\section{PURELY VERTICAL SHIP MOTION}

A stationary semi - trivial solution of equations (3.4) is

$$
\begin{aligned}
& a=0, \quad \psi=\psi_{0}, \\
& R=R_{0}, \quad \theta=\theta_{0},
\end{aligned}
$$

where $\psi_{0}$ is an arbitrary constant and $R_{0}, \theta_{0}$ are constants satisfying the relations

$$
\begin{aligned}
& h R_{0}+\sigma \eta \sin \theta_{0}=0, \\
& \Gamma R_{0}-\frac{3}{4} \beta R_{0}^{3}+\sigma \eta^{2} \cos \theta_{0}=0 .
\end{aligned}
$$

This solution corresponds to the vertical motion of the ship, while its angular motion remains unexcited.

Eliminating the phase $\theta_{0}$ from (4.2) we obtain an equation which defines the admissible values of the amplitude $R_{0}$ as a function of the excitation frequency $\eta$ :

$$
W\left(R_{0}^{2}, \eta^{2}\right)=0
$$

here

$$
\begin{aligned}
W\left(R_{0}^{2}, \eta^{2}\right) & =R_{0}^{2}\left[h^{2} \eta^{2}+\left(\Gamma-\frac{3}{4} \beta R_{0}^{2}\right)^{2}\right]-\sigma^{2} \eta^{4} \\
\varepsilon \Gamma & =\eta^{2}-k^{2}
\end{aligned}
$$

This relationship can be expressed approximately as

$$
\eta^{2}=k^{2}+\frac{3}{4} \varepsilon \beta R_{0}^{2} \pm \varepsilon k \sqrt{\frac{\sigma^{2} k^{2}}{R_{0}^{2}}-h^{2}},
$$

and is plotted in Fig. 2 for the parameters $k=2, h=10^{-1}, \sigma=4.5 \cdot 10^{-2}, \beta=0$ (curve 1) and $\beta=1$ (curve 2). With very small values of $\sigma$, the amplitude $R_{0}$ is almost a small constant: $R_{0}^{2} \simeq k^{2} \sigma^{2} / h^{2}$.

To study the stability of the semi - trivial solution (4.1) one lets

$$
a=\delta a, \quad \psi=\psi_{0}+\delta \psi, \quad R=R_{0}+\delta R, \quad \theta=\theta_{0}+\delta \theta .
$$

The following variational equations will be obtained

$$
\begin{aligned}
\frac{d}{d t}(\delta R) & =-\frac{\varepsilon}{2}\left(h \delta R+\sigma \eta \cos \theta_{0} \delta \theta\right) \\
R_{0} \eta \frac{d}{d t}(\delta \theta) & =-\frac{\varepsilon}{2}\left[\left(\Gamma-\frac{9}{4} \beta R_{0}^{2}\right) \delta R-\sigma \eta^{2} \sin \theta_{0} \delta \theta\right], \\
\frac{d}{d t}(\delta a) & =-\frac{\varepsilon}{2}\left[c+\sigma \eta \sin 2 \psi_{0}-\eta R_{0} \sin \left(\theta_{0}-2 \psi_{0}\right)\right] \delta a \\
0 & =\left[2 \Delta+\sigma \eta^{2} \cos 2 \psi_{0}+\eta^{2} R_{0} \cos \left(\theta_{0}-2 \psi_{0}\right)\right] \delta a .
\end{aligned}
$$


From the first two equations of (4.6) and from (4.2) and (4.3) one can find after a short calculation the stability condition

$$
\frac{\partial W}{\partial R_{1}}>0
$$

which is imposed upon the resonant curve (see heavy lines in Fig.2) of the vertical motion of the ship.

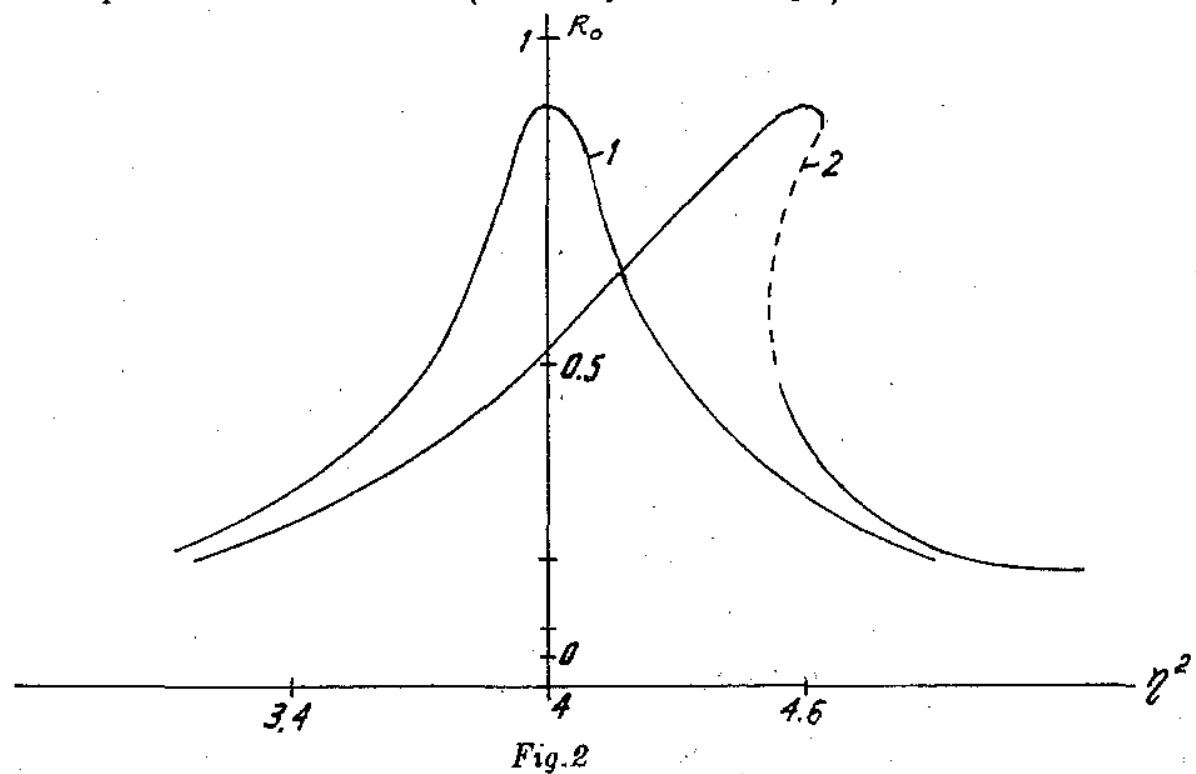

The boundary of the instability region for the appearance of a parametric resonance of angular ship motion is determined from the last two equations of (4.6) as

$$
\begin{aligned}
& c+\sigma \eta \sin 2 \psi_{0}-\eta R_{0} \sin \left(\theta_{0}-2 \psi_{0}\right)=0, \\
& 2 \Delta+\sigma \eta^{2} \cos 2 \psi_{0}+\eta^{2} R_{0} \cos \left(\theta_{0}-2 \psi_{0}\right)=0
\end{aligned}
$$

Eliminating the phases $\psi_{0}, \theta_{0}$ gives

$$
\begin{aligned}
\eta^{2} c^{2}+4 \Delta^{2} & =\eta^{4}\left(\sigma^{2}+R_{0}^{2}\right)+2 \eta^{2} R_{0}^{2}\left(\frac{3}{4} \beta R_{0}^{2}-\Gamma\right) \\
\varepsilon \Delta & =\frac{1}{4} \eta^{2}-1
\end{aligned}
$$

or

$$
\eta^{2} \simeq 4 \pm 2 k \varepsilon \sqrt{k^{2}\left(\sigma^{2}+R_{0}^{2}\right)-c^{2}+2 R_{0}^{2}\left(\frac{k^{2}-\eta^{2}}{\varepsilon}+\frac{3}{4} \beta R_{0}^{2}\right)}
$$

where $R_{0}$ satisfies equation (4.3). The relation (4.9) is plotted in Fig.3 for the case $\beta=1$, $c=10^{-1}, h=10^{-1}$, and $k=1.9$ (curve 1 ), $k=2$ (curve 2), $k=2.1$ (curve 3 ). These curves are approximately parabolic and the instability region is located above the parabola (see shaded region in Fig.3). For sufficently small values of the excitation $(\sigma)$, the semi - trivial solution remains stable. Corresponding to every instability region there exists a "theshold ${ }^{n} \sigma=\sigma_{0}$ which must be exceeded before instability can occur.

Taking into account curve. 2 in Fig. 3 , one can see that for $\sigma=4.5 \cdot 10^{-2}$ and $2.75 \leq \eta^{2} \leq 4.9$ the parametric vibration of angular motion may occur. So, in the interval $2.75 \leq \eta^{2} \leq 4.9$ the ship motion will not be characterised only by the resonant curve in Fig.2. Outside the mentioned interval the angular motion of the ship will be zero and the ship motion is characterised only by 
the resonant curve in Fig.2. In the last case the amplitude of ship vibration will be small and almost constant. Therefore, for the case considered, the purely vertical motion (without angular motion) occurs only with small amplitude. The strong vertical motion will be accompanied by the angular one.

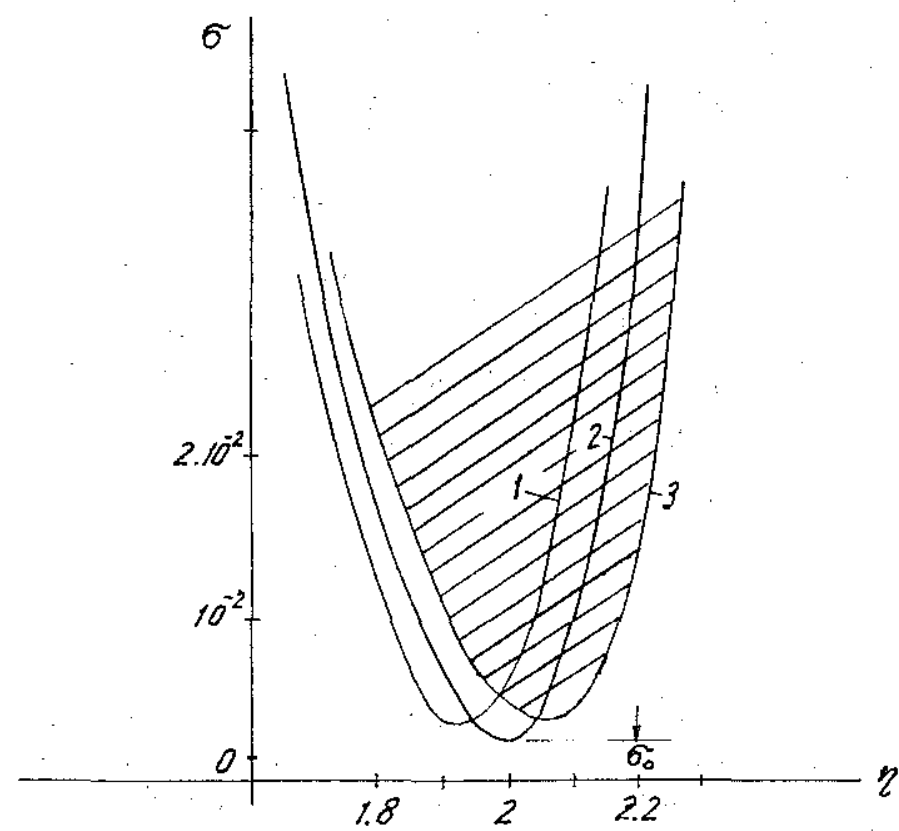

Fig. 9

\section{COUPLING BETWEEN VERTICAL AND ANGULAR MOTIONS}

The non - trival stationary solution of equations (3.4) with $a \neq 0, R \neq 0$ is determined from the relation:

$$
\begin{aligned}
& \sigma \eta^{2} \sin \theta+\frac{1}{4} \mu \eta^{2} a^{2} \sin (\theta-2 \psi)=-h \eta R \\
& \sigma \eta^{2} \cos \theta+\frac{1}{4} \mu \eta^{2} a^{2} \cos (\theta-2 \psi)=\left(\frac{3}{4} \mu R^{2}-\Gamma\right) R \\
& \sigma \eta^{2} \sin 2 \psi-R \eta^{2} \sin (\theta-2 \psi)=-c \eta \\
& \sigma \eta^{2} \cos 2 \psi+R \eta^{2} \cos (\theta-2 \psi)=-\left(2 \Delta+\frac{1}{4} a^{2}\right)
\end{aligned}
$$

This solution corresponds to the simultaneous vertical and angular motions of the ship. Eliminating the phase variables in these equations we obtain the following expression giving the dependence of the amplitudes of vibration $a, R$ on the frequency $\eta$ of the exciting force:

$$
\eta^{2}\left(c^{2}-h^{2} R^{2}\right)+\left[2 \Delta+\frac{1}{4} a^{2}-\frac{1}{4} \mu \eta^{2} a^{2}\right]^{2}=R^{2}\left[\eta^{2}-\Gamma+\frac{3}{4} \beta R^{2}\right]^{2}
$$

This relationship is plotted in Fig.4 for the case $\beta=1, k=2, h=c=0.1$ and $\mu=0.05$. From Fig.4 it is seen that, increasing $\eta$ from the resonant value $(\eta=2)$ and keeping constant the amplitude of vertical motion, the amplitude of angular ship vibration (a) decreases, and at a constant value of the excitation frequency $(\eta)$ the amplitudes of vertical and angular ship vibrations either increase or decrease simultaneously. 


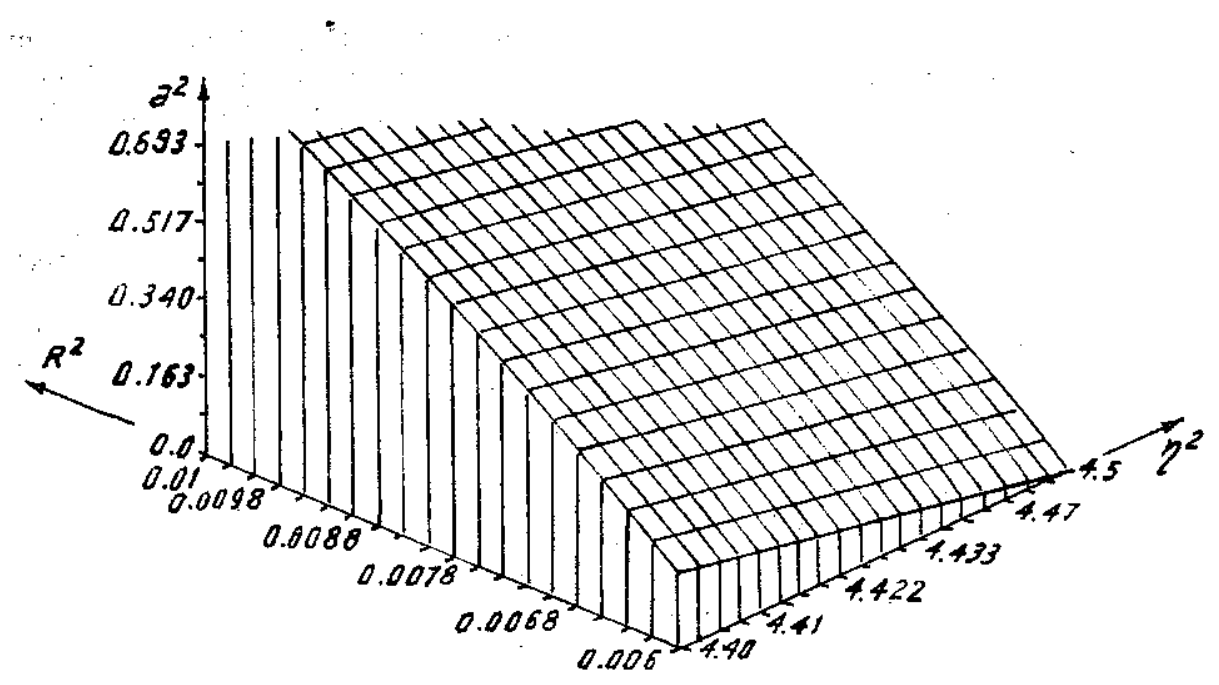

Fig.4

\section{CONCLUSION}

The nonlinear model simulation of coupling between vertical and angular. ship motions has been considered. The nonlinear terms in the motion equations have essential influence on both the shape of the response curve and the instability region in comparison with the linear equations $\mid 1$, 2]. The condition for the appearance of a purely vertical vibration of the ship has been derived. In the case considered this vibration occurs only with small amplitude and the strong vertical ship vibration is always accompanied by angular motion. The stationary simultaneous vertical and angular motions of the ship have been studied too.

\section{REFERENCES}

1. Tondl A., Nabergoj R. Model Simulation of parametrically excited ship rolling. J. Nonlinear Dynamics 1 (131-141), 1990. Kluwer Academic Publishers Netherlands.

2. Nabergoj R. Parametric resonance of a spring - pendulum system. Eighth world congress on the theory of machine and mechanisms, Prague, czechoslovakia, August 1991 (299 - 302).

3. Bogoliubov N. N., Mitropolxki Yu. A. Asymptotic methods of the theory of nonlinear vibrations, Moscow, 1974.

Received March 28, 1992

\section{MÔ HINH PHI TUYẾN MÔ PHỎNG CHUYEึ̉N ĐỘNG TÀU THƯY}

Trong bào báo này mô hình tuyến tính của Tondl $A$. và Nabergoj $R$. [1, 2] về sự lắc ngang và chuyển động thẳng đứng của tàu thủy được mł rộng cho trường hợp phi tuyến, tạo nên do đặc trưng đàn hồi và kể đến các số hạng bậc cao trong khai triển các hàm lượng giác. Đã xét đến khả năng xẩy ra đờng thời cộng hướng cưỡng bức (đối với chuyển động thăng đứng) và cộng hương thông số (đối với chuyển động lǻc ngang) của tàu thủy; cũng như đã nghiên cúru chỉ riêng chuyển động thăng đứng mà không có chuyển động lắc ngang của tàu.

Chuyển động đồng thời thẳng đứng và lắc ngang của tàu có đặc điểm là ớ cùng một tần số kích động các biền độ dao động đứng và dao động lắc ngang cùng tăng hoặc cùng giăm. Khi tăng tần số kích động từ giá trị cộng hướng và giữ cho biên độ dao động đứng không đổi thì biên độ dao động lắc ngang giăm. 